\title{
Spotlight on Hand-Foot Syndrome
}

\section{Bassam Abdul Rasool Hassan*}

Clinical Pharmacy Discipline, School of Pharmaceutical Sciences, University of Sains Malaysia, 11800, Minden, Penang, Malaysia

\section{Introduction}

This clinical syndrome was firstly discovered and reported in 1974 by Zuehlke RL. It is a clinical situation usually occurs or takes place among cancer patients after receiving chemotherapy treatment, it characterize by reddening, swelling, numbness and desquamation on palms and soles. Moreover, these skin changes have two more features which are well defined or drew on the skin, and they will disappear within few weeks after termination or finishing of chemotherapy treatment. There are various theories to clarify hand food syndrome pathogenesis, but the most acceptable one indicate that the variations among cells i.e., epidermal cells and eccrine glands, vascular anatomy and temperatures are the main hand-foot syndrome pathogenesis.

\section{Clinical Causes}

This syndrome consider as the main adverse reaction of chemotherapy drug. The chemotherapy drugs that are highly associated with hand-foot syndrome are cytarabine, doxorubicin, and fluorouracil and its prodrug capecitabine.

\section{Clinical Signs and Symptoms}

There are various signs and symptoms associate with hand-foot syndrome, and their variations will mainly related with the syndrome severity.

Signs and symptoms associated with mild to moderate hand-foot syndrome are the following:

1- Redness

2- Swelling

3- Presence of tingling and/or burning

4- Tenderness

5- Tightness

While signs and symptoms associated with severe hand-foot syndrome are:

1- Cracked and/ or flaking skin

2- Blisters and/ or sores on the skin

3- Severe pain

4- Difficulty in walking and/ or using hands

\section{Supportive and Palliative Care}

Some tips that can be used by cancer patients treated with chemotherapy which can help in preventing, palliating or reducing incidence and/ or increase severity of this syndrome:

1- Reduce frequency of cancer patient feet and hands exposure to hot water.

2- Careful drying of their skin after each bath.

3- Exposure your hands and feet to cool running water or put them in an ice pack for 15 to 20 minutes per day.

4- Avoid unnecessary activities that might lead to cracking skin and avoid exposure to harsh chemical too.
5- Cancer patients should not to walk barefoot and should not use thick socks to reduce friction in their feet.

\section{Medical Treatment}

Various types of medical treatments can be used when hand-foot syndrome takes place:

1- Topical anesthetics to reduce pain fillings.

2- Anti-inflammatory creams like cortisone creams.

3- Skin moisturizing creams.

4- Ice packs.

5- Pain killers like ibuprofen.

\section{Conclusion}

Therefore it is a very important point for the open access journals to encourage researchers and clinicians to work hard in order to clarify the main problems associated with incidence of hand-foot syndrome. Moreover, encourage them to detect and develop new generations of effective treatments, which will help to overcome this medical problem.
*Corresponding author: Bassam Abdul Rasool Hassan, Clinical Pharmacy Discipline, School of Pharmaceutical sciences, University of Sains Malaysia, 11800, Minden, Penang, Malaysia, Tel: +60164230950, E-mail: bassamsunny@yahoo.com

Received March 15, 2014; Accepted March 17, 2014; Published March 20, 2014

Citation: Hassan BAR (2014) Spotlight on Hand-Foot Syndrome. Nat Prod Chem Res 2 :e107. doi:10.4172/2329-6836.1000e107

Copyright: (c) 2014 Hassan BAR. This is an open-access article distributed under the terms of the Creative Commons Attribution License, which permits unrestricted use, distribution, and reproduction in any medium, provided the original author and source are credited. 